\title{
Evidências de Circulação de Brisa Vale-Montanha na Serra da Mantiqueira: Cidade de Itajubá - MG
}

\author{
Evidences of Mountain-Valley Breeze Circulation in the "Serra da \\ Mantiqueira": Itajubá City - MG State
}

Michelle Simoes Reboita ${ }^{1}$, Arcilan Assireu ${ }^{2}$ Lucas Chilelli da Silva ${ }^{3}$, Nancy Rios ${ }^{4}$

1,2,3,4 Universidade Federal de Itajubá - Unifei - Itajubá - MG, Brasil

\begin{abstract}
Resumo
A cidade de Itajubá, MG, localizada na Serra da Mantiqueira, apresenta topografia do tipo ondulada-montanhosa, sendo que grande parte da cidade está inserida num vale, fato que favorece o desenvolvimento de circulação de brisa vale-montanha. Diante disso, o objetivo do presente estudo é caracterizar essa circulação através de dados de direção e intensidade do vento obtidos por uma estação meteorológica automática situada no campus da Universidade Federal de Itajubá. Foi constatado que a brisa de montanha se estabelece entre 15-16 horas local (HL) e tem sua máxima intensidade entre 21-22 HL. Já a brisa de vale se estabelece entre 07-08 HL e tem a sua máxima intensidade entre 11-14 HL. Esses resultados mostram que a brisa de montanha é mais duradoura, o que pode estar associado à influência do efeito de aquecimento urbano nos gradientes horizontais de pressão entre o vale e a região montanhosa.
\end{abstract}

Palavras-chave: brisa vale-montanha, intensidade dos ventos, Itajubá

\begin{abstract}
Itajubá is a city located in an important Brazilian mountains chains named Serra da Mantiqueira. The relief is predominantly marked by undulating topography of the type-hill, and much of the city is set in a valley, a fact that favors the development of mountain-valley breeze circulation. This paper aims to characterize the mountain-valley breeze from wind data obtained by an automatic weather station located on the campus of the Federal University of Itajubá. The mountain breeze occurs between 15-16 local hour (LH) showing its maximum intensity between 21-22 LH, while the valley breeze occurs between 07-08 LH with maximum intensity between 11-14 LH. The results show that the mountain breeze is more persistent, which may be associated with the influence of the effect of heating for the horizontal pressure gradients between the valley and the mountains.
\end{abstract}

Keywords: mountain-valley breeze, wind intensity, Itajubá 


\section{Introdução}

O vento, que é o escoamento horizontal do ar, dependente da presença de gradientes horizontais de temperatura que, por sua vez, desenvolvem gradientes horizontais de pressão. Quando os gradientes térmicos ocupam grandes extensões originam circulações de grande escala que são influenciadas pela força de Coriolis e configuram os padrões de circulação geral observados na atmosfera (Kousky e Elias, 1982). Quando os gradientes térmicos ocupam extensões mais reduzidas da superfície terrestre, a circulação produzida atua apenas regionalmente sendo, portanto, chamada de circulação local e só é influenciada de forma secundária pela força de Coriolis, ou em outras palavras, o padrão do vento resultante pode ser analisado sem considerações sobre a força de Coriolis (Moraes et al., 1992).

As circulações locais integram o grupo dos fenômenos de mesoescala, isto é, que possuem duração de horas a dias e resolução espacial variando entre poucos quilômetros a cerca de $103 \mathrm{~km}$ (Stull, 2000). Dentre as circulações locais têm-se as circulações de vale e montanha. Em regiões de vale circundado por topografia elevada há geralmente um escoamento que se dirige do vale para a montanha durante o dia e da montanha para o vale durante a noite. Durante o dia, o ar sobre a face das montanhas que estão voltadas para o sol aquece mais rapidamente do que o ar sobre o vale. Nesse caso, surge um gradiente de pressão que aponta do vale para a montanha e origina as chamadas brisas de vale (ventos anabáticos). À noite, o ar da montanha se resfria mais rapidamente do que o ar sobre o vale. Dessa forma, o escoamento se dirigirá da montanha para o vale gerando brisas de montanhas (ventos catabáticos). De acordo com Nieuwolt e McGregor (1977), os ventos anabáticos podem ser facilmente reconhecidos, pois são, frequentemente, acompanhados pela formação de nuvens cumulus próximas ao topo das montanhas ou sobre escarpas.

Estudos sobre circulação de vale e montanha são escassos na literatura. Entre os existentes, pode-se citar o de Hindman (1973) que investigou o motivo de períodos com e sem nuvens stratus no interior do Redwood Creek Valley no norte da Califórnia em novembro de 1971. Esse autor associou a ausência de stratus com a circulação dentro do vale. Isto é, o ar eleva-se ao longo dos lados do vale e subside no centro do vale inibindo a convecção. Já Stewart et al. (2002) descreveram as características climatológicas (por exemplo, a hora do dia em que o vento muda de direção) das circulações induzidas termicamente em quatro regiões da Intermountain no oeste dos Estados Unidos. No Brasil, mais precisamente na região sudeste, Sakuragi e Souza (2000) simularam a circulação de vale-montanha no Vale do Paraíba durante 24 horas (o dia escolhido foi $1^{\circ}$ de fevereiro) com o Regional Atmospheric Modeling System (RAMS). Segundo os autores, às 07 horas local, período de maior resfriamento radiativo, há o domínio da brisa de montanha que se dirige para o interior do vale. Entretanto, à medida que as horas passam, a superfície continental aquece e o vento muda de direção o que resulta na brisa de vale. Uma das implicações importantes deste processo é que, sob determinadas condições orográficas, as chuvas ocorrem adjacentes às encostas, como constatado, por exemplo, ao redor do Vale do Paraíba por Vemado (2012).

A cidade de Itajubá, localizada no sul do Estado de Minas Gerais, é separada do Vale do Paraíba pela Serra da Mantiqueira. As características topográficas de Itajubá também podem favorecer uma circulação dirigida termicamente. Portanto, este estudo tem como objetivo caracterizar a ocorrência de circulação de vale e montanha nesta região. Para tanto, serão utilizados dados medidos numa estação meteorológica automática localizada no Campus da Universidade Federal de Itajubá (Unifei) no período de abril de 2010 a março de 2012. Esse estudo está dividido da seguinte maneira: na seção 2 é apresentada a metodologia de estudo, na seção 3 os resultados e, por fim, na seção 4 as conclusões.

\section{Metodologia}

\subsection{Caracterização da Área de Estudo}

A cidade de Itajubá está localizada no sul do Estado de Minas Gerais e possui coordenadas $22^{\circ} 30^{\prime}$ $30^{\prime \prime} \mathrm{S}$ e $45^{\circ} 27^{\prime} 20^{\prime \prime} \mathrm{W}$ (Figura 1). A topografia de Itajubá é do tipo ondulada-montanhosa, pois cerca de $10 \%$ do território apresenta-se plano, $12 \%$ ondulado e $78 \%$ montanhoso (Prefeitura Municipal de Itajubá, 2012).

\subsection{Procedimentos}

Foram utilizados dados de intensidade e direção do vento medidos a cada 10 minutos na estação meteorológica automática da Unifei, que está localizada na latitude $22^{\circ} 24^{\prime} 46^{\prime \prime}$ S e longitude $45^{\circ} 24^{\prime} 06^{\prime \prime} \mathrm{W}$ a 850 metros de altitude. Os dados compreendem o período de abril de 2010 a março de 2012, com exceção dos meses de dezembro de 2010 e 2011 quando a estação apresentou problemas de medição e, por isso, os dados recebidos neste período não são confiáveis. É importante destacar que antes da realização do estudo os dados de intensidade e direção do vento passaram por um controle de qualidade a fim de detectar possíveis dados errôneos ou falhas dos instrumentos. Embora o 

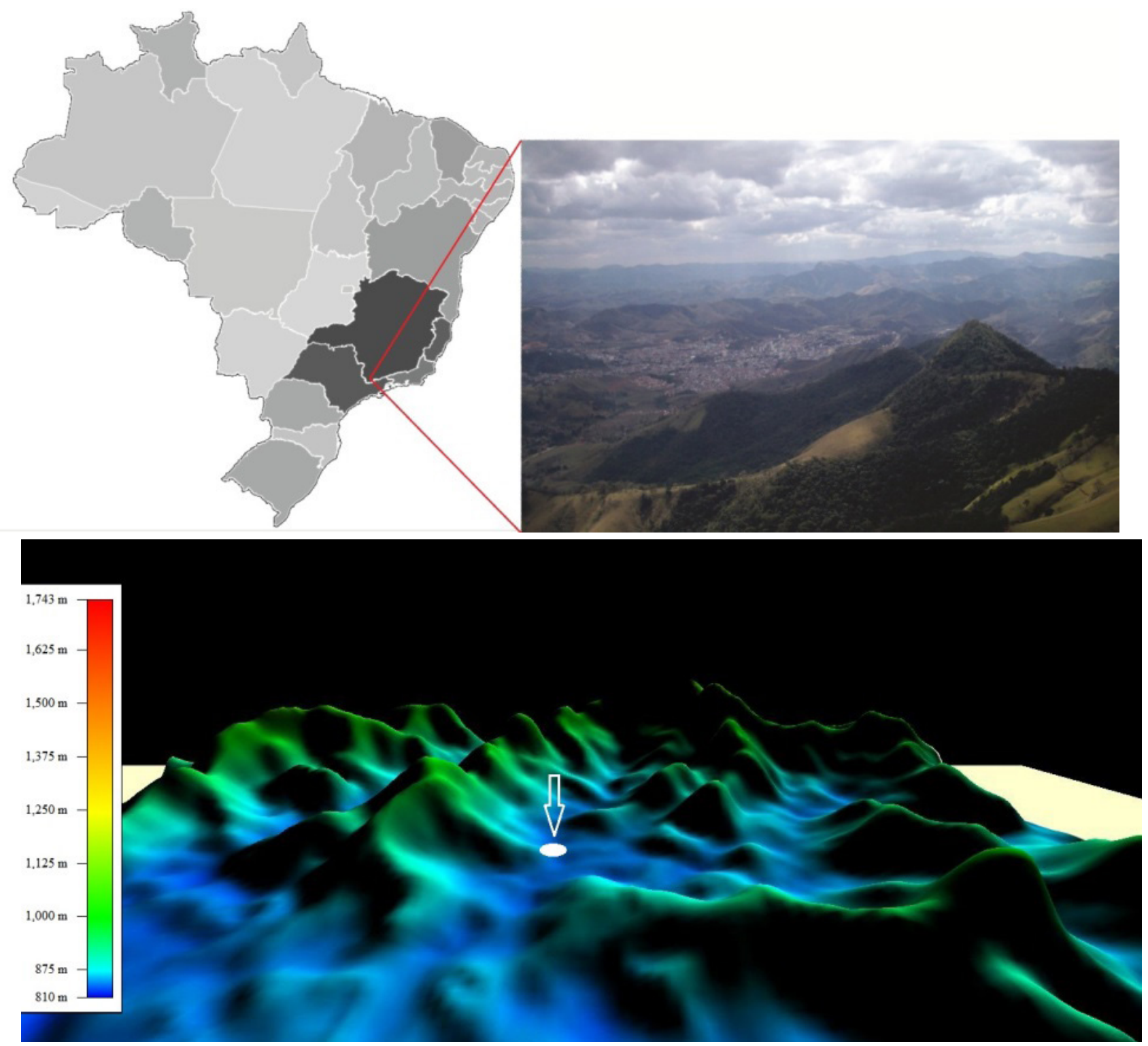

Figura 1 Painel superior: localização de Itajubá em relação ao Brasil e ao Estado de Minas Gerais; painel inferior: modelo de elevação (metros) ao redor da estação meteorológica da Unifei que está identificada com um círculo.

período de dados não seja muito extenso, ele é representativo do fenômeno estudado (como será visto nos resultados). Isso também concorda com Braga e Krusche (2000) que caracterizaram a brisa marítima-terrestre na cidade de Rio Grande, RS, com apenas 4 anos de dados, mas com muitos períodos falhos.

Para a identificação da circulação de brisa vale e montanha elaborou-se uma rosa dos ventos para cada hora do dia (Figura 4). Os dados com frequência de 10 minutos foram filtrados a partir de médias diárias aplicadas sobre a intensidade e direção do vento. Estes dados foram, então, usados no software Wind Roses Plot (WRPLOT; http://www.weblakes.com/ products/wrplot/index.html) onde foram geradas as rosas do vento.

A rosa dos ventos consiste de uma figura onde é possível relacionar a intensidade e direção dos ventos com sua frequência de ocorrência. Os círculos concêntricos indicam a porcentagem de ocorrência de cada direção do vento (norte, nordeste, leste, sudeste, sul, sudoeste, oeste e noroeste). Já as cores indicam a intensidade do vento, conforme a escala localizada ao lado direito da rosa dos ventos. Para calcular a porcentagem de ocorrência de uma determinada faixa de velocidade dos ventos é preciso considerar o respectivo intervalo que delimita uma faixa de cor. Quanto à direção do vento, a rosa dos ventos mostra a direção de onde sopram os ventos em direção à estação de medição (no caso, o centro da rosa dos ventos). Assim, por exemplo, os ventos de sul (180) são aqueles que estão entre a borda sul e o centro da rosa dos ventos. Como será discutido adiante, o referencial 
assumido neste trabalho, por conta da morfometria da área de estudo, faz com que os ventos de sul sejam do vale para a montanha enquanto os de norte sejam da montanha para o vale (Figura 3).

A fim de comparar espacialmente a temperatura da superfície na cidade de Itajubá com os arredores, utilizaram-se os produtos MYD11A1 do sensor Moderate Resolution Imaging Spectroradiometer (MODIS) que está acoplado aos satélites de órbita polar Terra e Aqua. Esses satélites são sincronizados com a órbita terrestre de tal forma que a trajetória do satélite Terra é de norte para sul (passando sobre o equador pela manhã), enquanto a trajetória do Aqua é de sul para norte (passando sobre o equador à tarde). Ambos os sensores cobrem toda a superfície terrestre de um a dois dias, e a aquisição de dados pode ser feita em 36 bandas espectrais (Anderson et al., 2003).

Os produtos MYD11A1 do sensor MODIS/ Aqua são gerados em condições de céu claro utilizando algoritmos baseados nas médias das emissividades das bandas 31 (10,780 - 11,280 $\mu \mathrm{m})$ e banda $32(11,770$ - 12,270 $\mu \mathrm{m}$ ) do sensor MODIS (Petitcolin e Vermote, 2002; Wan e Li, 1997). Os produtos MYD11A1 são disponibilizados em células de 1200 x 1200 pixels, com resolução horizontal de 1000 m (EOSDIS, 2009). A temperatura de superfície $\left({ }^{\circ} \mathrm{C}\right)$ correspondente a cada célula é obtida pela equação:

\section{$T_{94}=\left(b_{1}-0,02\right)-273,15$}

onde $b_{1}$ é o grânulo original MYD11A1 e 0,02 é o fator de escala desse produto.

As temperaturas de superfície foram analisadas para diferentes dias do período em estudo, para o horário das 03 UTC e 15 UTC (00 e 12 horas local), correspondentes aos horários da passagem do satélite sobre a região de estudo. Adicionalmente, a mancha urbana da cidade de Itajubá foi delimitada para o cálculo da temperatura média dos pixels contidos na área dessa região. Uma vez obtida a temperatura média da mancha urbana, calculou-se o mapa de anomalias para todo o município de Itajubá em relação a esse valor médio. Nesse estudo só será mostrado um exemplo dos mapas de anomalias para cada horário supracitado (Figura 5).

\section{Resultados}

A Figura 2 mostra a rosa dos ventos obtida com todos os dados médios horários, no período de abril de 2010 a março de 2012, na estação meteorológica da Unifei. A direção do vento com maior porcentagem de ocorrência é a norte $(40 \%)$ que é

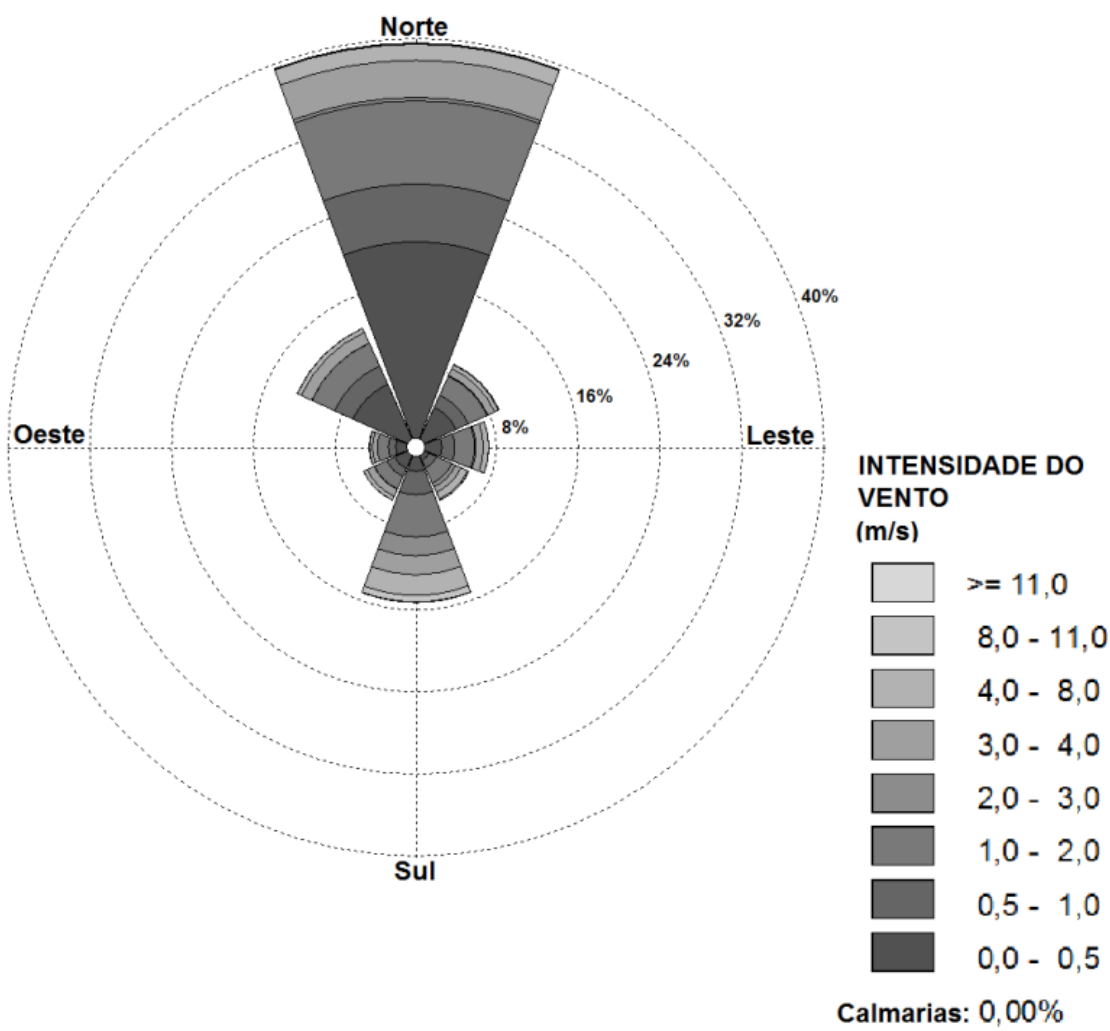

Figura 2 Rosa dos ventos de todo o período em estudo (abril de 2010 a março de 2012), obtida a partir de dados médios horários. 


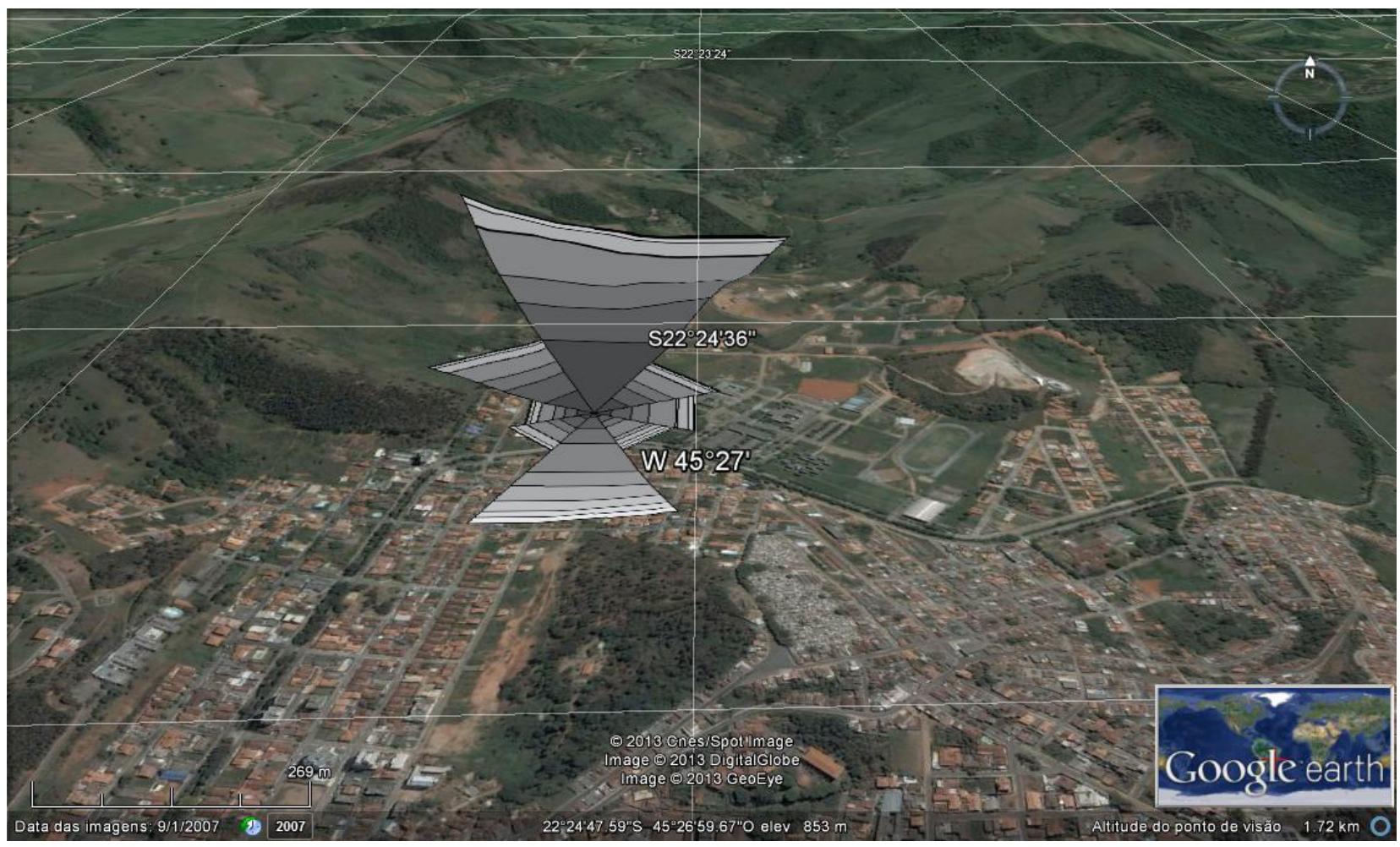

Figura 3 Projeção da rosa dos ventos mostrada na Figura 2 sobre a cidade de Itajubá.

seguida da sul $(15,2 \%)$ e da noroeste $(12,8 \%)$. Com relação às intensidades do vento, pode-se dizer que essas permanecem em grande parte do tempo ( $44 \%$ das ocorrências) com valores baixos, em torno de 0,1 a $0,5 \mathrm{~m} / \mathrm{s}$; essa faixa é seguida pela de 1,0 a $2,0 \mathrm{~m} / \mathrm{s}$ ( $22 \%$ das ocorrências). De maneira geral, predominam ventos de quadrante norte e sul na Figura 2. A ocorrência de ventos de quadrantes opostos pode ser um indicativo da ocorrência de circulação de brisa vale e montanha na região em estudo. Para avaliar essa hipótese, inicialmente, projetou-se a rosa dos ventos sobre a figura da topografia da região de estudo (Figura 3). Nesta é evidente que há um escoamento que desce a montanha em direção ao vale (ventos de quadrante norte) e do vale em direção à montanha (ventos de quadrante sul).

Como na Figura 3 é observado que os ventos de quadrante norte dirigem-se da região mais elevada (montanha) em direção à cidade de Itajubá, local onde se situa a estação meteorológica referida nesse estudo, a hipótese é que esses ventos estejam associados com a brisa de montanha e que ocorram preferencialmente no período noturno. Já os ventos de quadrante sul devem estar associados com a brisa de vale e com ocorrência mais frequente no período diurno. Através da análise temporal das rosas do vento construídas para cada hora do dia (Figura 4) essas hipóteses são confirmadas.

A Figura 4 mostra que entre 06-07 h (horas local) a direção predominante do vento ( $50 \%$ das ocorrências) é a norte, porém nota-se um ligeiro aumento da ocorrência de direções nordeste em relação ao horário precedente (05-06 h). Entre 07-08 h também há um pequeno aumento da ocorrência de ventos de nordeste em relação ao horário anterior, mas a característica marcante nesse horário é a ocorrência de ventos de direção sul (12\% das ocorrências). Portanto, sugere-se que entre 07-08 h seja o horário em que a brisa de vale começa a se estabelecer. À medida que as horas passam o número de ocorrências de ventos de direção sul aumenta enquanto as de norte diminuem; sendo que entre 09-12 h o número de ocorrências de ventos de direção sul é bem maior do que as de norte. Entre 12-14 h há ocorrência similar de ventos com direção sul e norte, entretanto, a partir das 14-15 h a ocorrência de ventos de sul começa a decrescer e as de oeste aumentar. Já entre 15-16 h a ocorrência de ventos de direção norte tem um ligeiro aumento em relação aos horários anteriores. Portanto, a partir desse horário a brisa de montanha parece se estabelecer.

Nos horários que seguem 15-16 h, a ocorrência de ventos com direções noroeste e norte aumenta enquanto as com direção sul diminui. O número de ocorrência de ventos com direção sul é mínimo entre 03-07 h, ou seja, no mesmo período em que o número de ocorrência de ventos com direção norte é máximo. Entre 06-07 h começa a aumentar a ocorrência de ventos de direção nordeste e entre $07-08 \mathrm{~h}$ aparecem ventos 

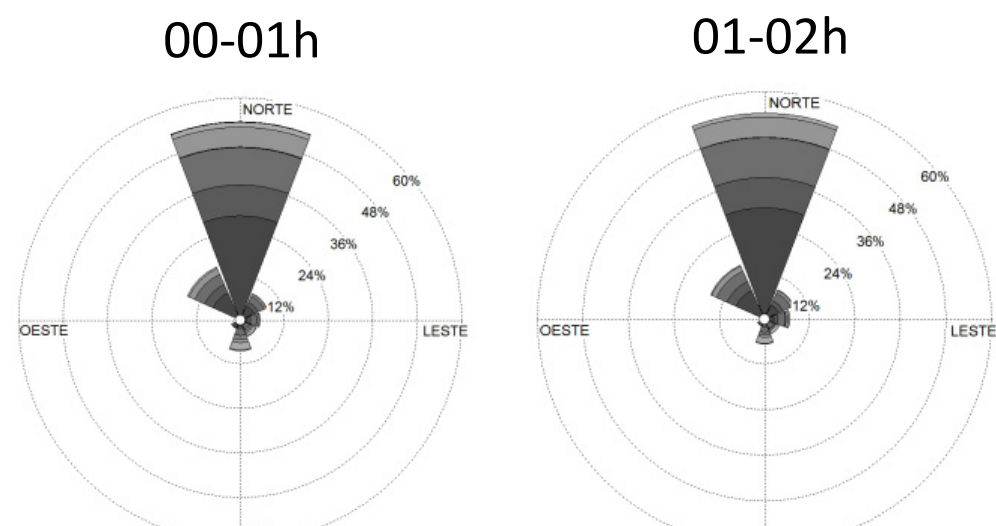

$02-03 h$
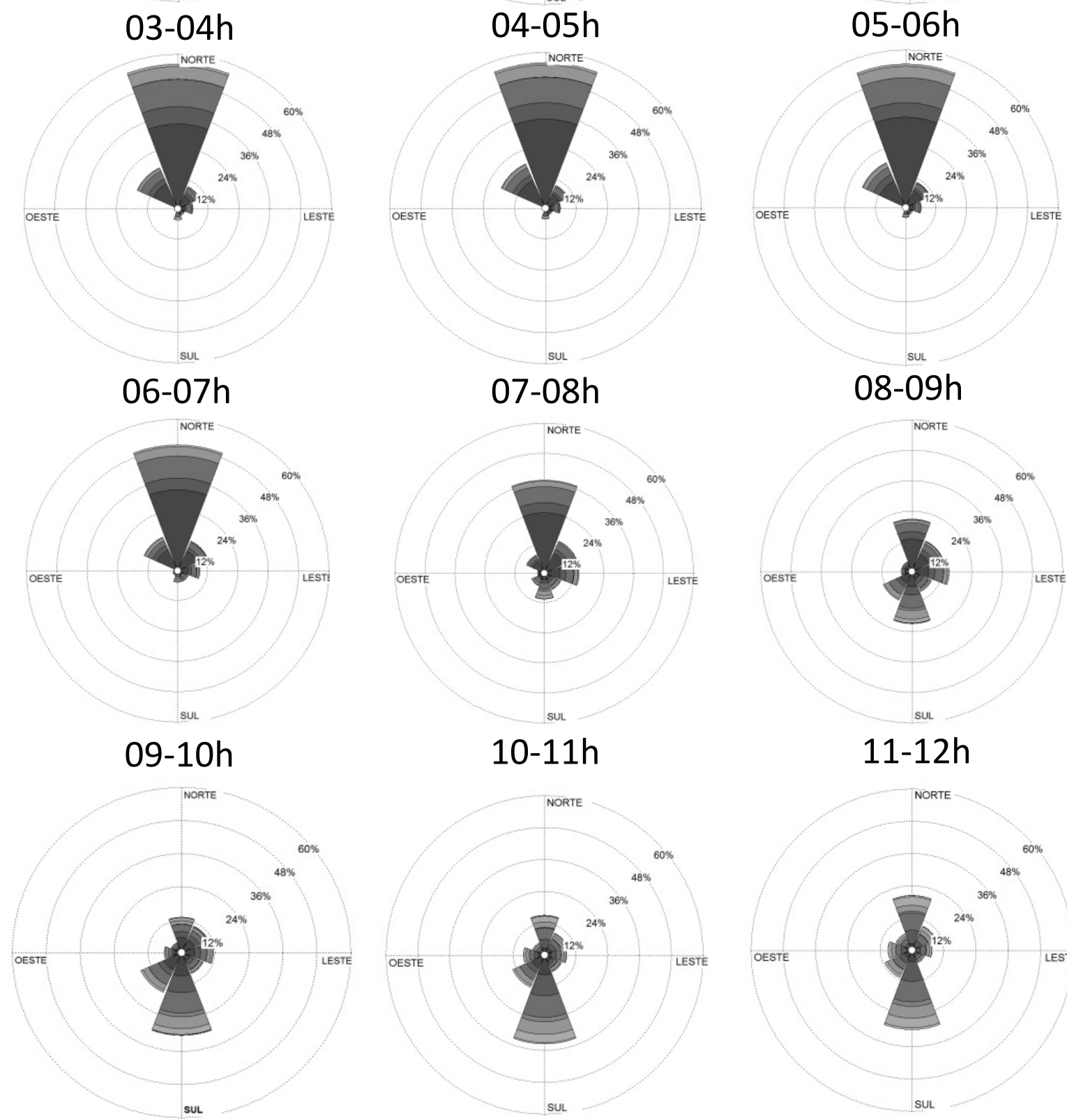

10-11h

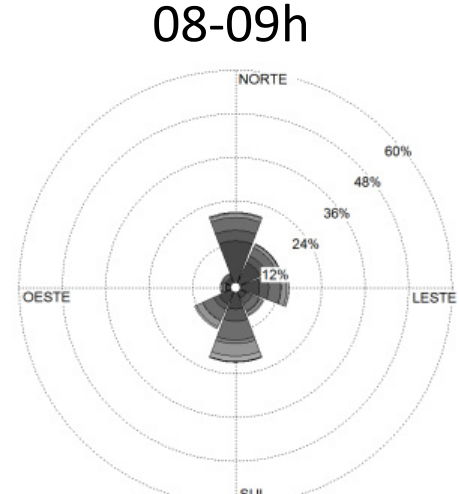

$11-12 h$
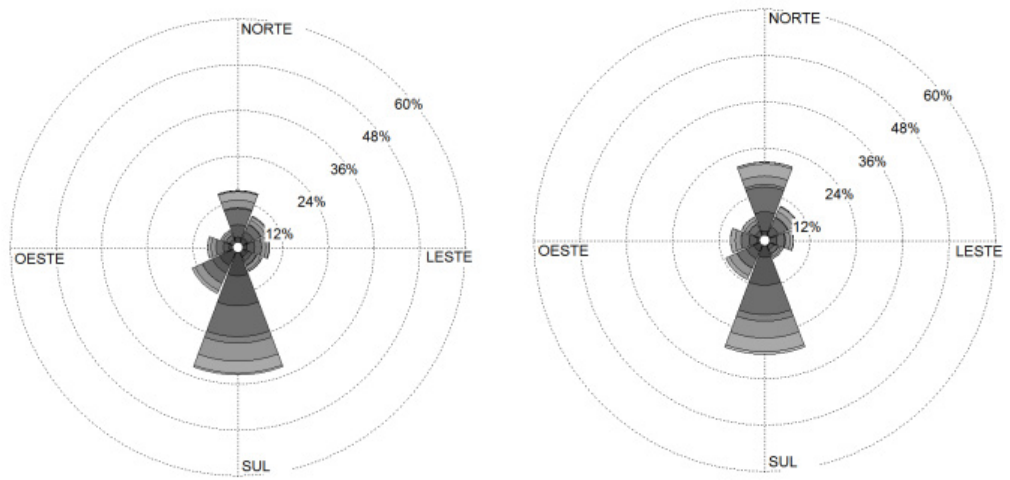

Figura 4 Evolução horária da direção do vento no período estudado. A escala de cores da intensidade é apresentada no último quadro. 

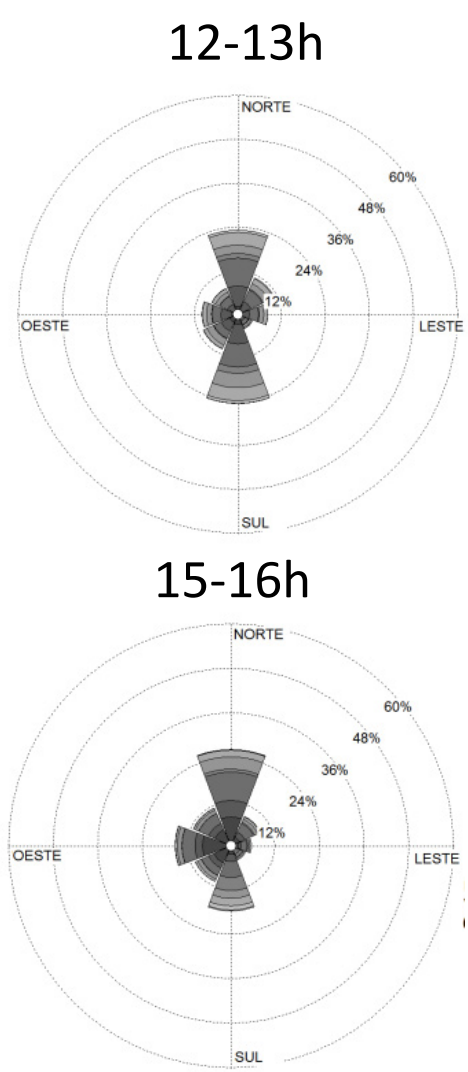

18-19h

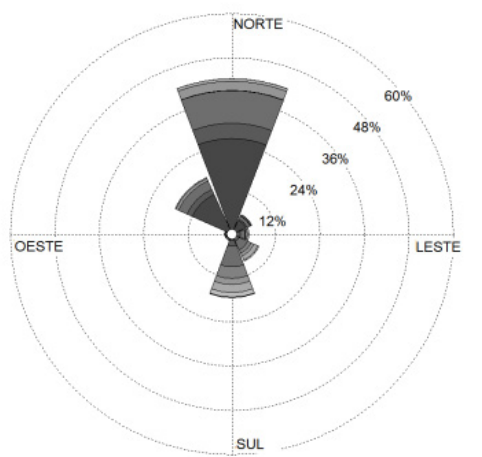

$21-22 h$

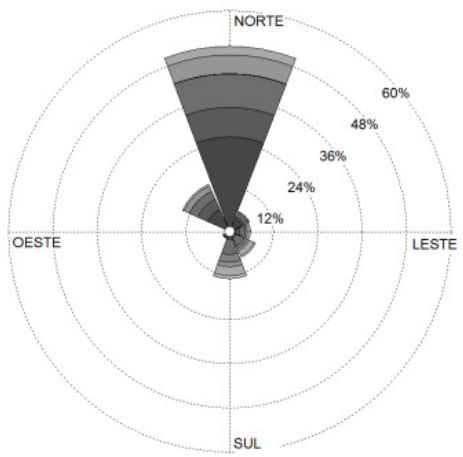

$13-14 h$

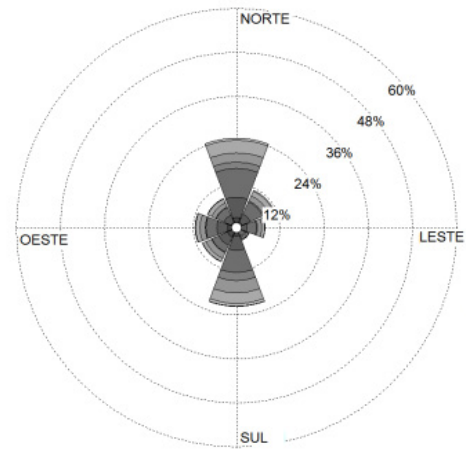

16-17h

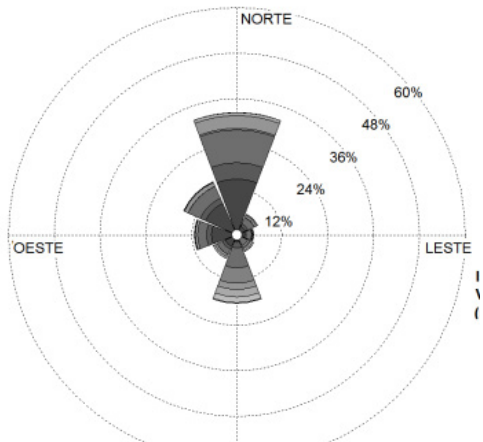

$19-20 \mathrm{~h}$

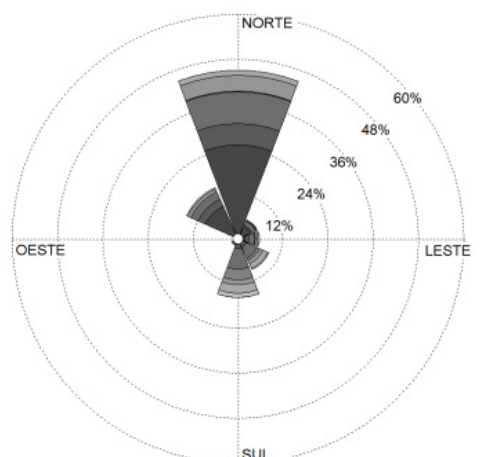

$22-23 h$

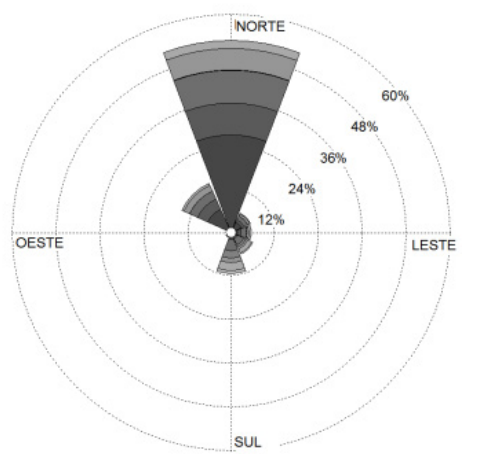

$14-15 h$

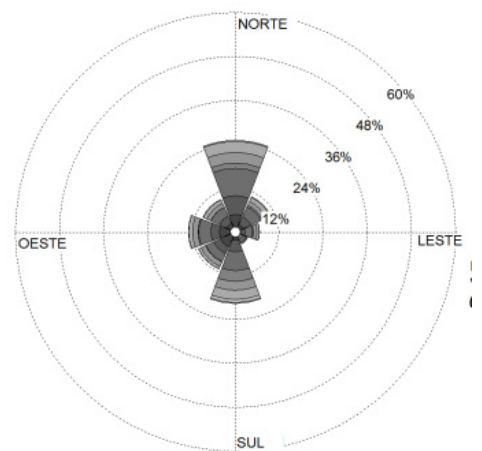

$17-18 h$

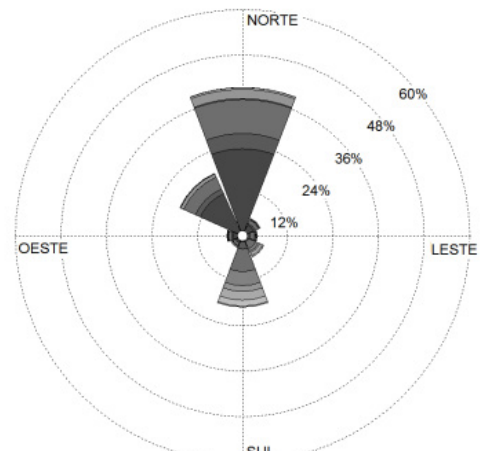

$20-21 h$

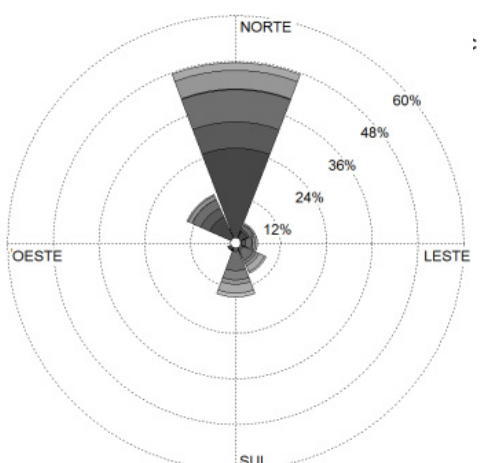

23-00h

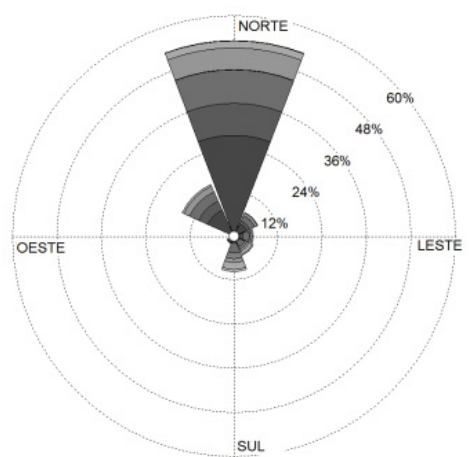

Figura 4: continuação. 


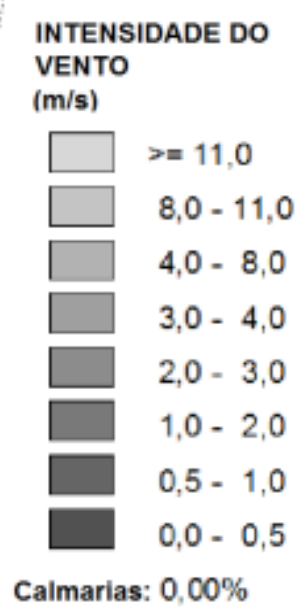

Figura 4: continuação.

com direção sul e o ciclo descrito se repete.

De acordo com Whiteman (2000), a fase de transição da brisa de montanha para a de vale ocorre ligeiramente após o nascer do sol, isto é, quando a radiação de onda curta recebida na superfície do planeta excede a sua perda por onda longa. Já a fase de transição da brisa de vale para a de montanha ocorre no final da tarde, ligeiramente antes do pôr do sol, quando a perda de energia por onda longa já é maior do que o recebimento de energia por onda curta. Os resultados do presente estudo indicam que a brisa de vale em Itajubá inicia entre 07-08 h o que concorda com Whiteman (2000), já a brisa de montanha parece estar adiantada (isto é, se estabelece mais cedo). Uma possível explicação para isso seria a influência do aquecimento diurno da região urbana de Itajubá, ou seja, um efeito de ilha de calor. Sugere-se que o aquecimento urbano anteciparia o gradiente horizontal de temperatura caracterizado pelo ar mais frio nos arredores da montanha e o mais quente na cidade (lembrar que nessa localidade a brisa de montanha se desloca em direção a cidade). Para avaliar o possível efeito do aquecimento urbano, construíram-se mapas de anomalia de temperatura do ar à superfície (temperatura dos pixels menos a média da temperatura dentro da mancha urbana de Itajubá na Figura 5) para os horários das 00 e 12 horas local e identificaram-se duas localidades na mesma banda de latitude nesses mapas: a estação meteorológica da Unifei dentro da cidade de Itajubá (círculo) e uma região sem urbanização com topografia similar a da cidade de Itajubá (quadrado). Um exemplo para o dia 04 de fevereiro de 2011 é mostrado na Figura 5. A primeira informação relevante dessa figura é que a região sem urbanização é mais fria do que a mancha urbana. Logo, isso sugere a ocorrência do efeito de ilha de calor em Itajubá. A segunda informação é que a diferença de temperatura entre os dois locais é mais acentuada durante o dia (Figura 5b). Portanto, esse fato pode justificar a maior duração da brisa de montanha em Itajubá, uma vez que o aquecimento urbano afeta os gradientes horizontais de temperatura montanha e vale.

A Figura 6 mostra a variação horária da intensidade do vento por mês do ano. Os valores de intensidade apresentados nessa figura são inferiores aos da Figura 4, pois são consideradas médias mensais, enquanto na Figura 4 os dados médios horários que acabam apresentando uma maior variação. Em geral, os ventos apresentam um mínimo de intensidade entre 05-06 h e uma máxima intensidade entre 11-14 h. Já entre 16-18 h os ventos apresentam um mínimo secundário e por volta das 21-22 h um máximo secundário. A mínima intensidade registrada entre 05-06 h está associada a maior equalização espacial da temperatura com consequentes menores valores de gradientes de pressão enquanto os máximos entre 11-14 h indicam o período de maior intensidade da brisa de vale.

\section{Conclusões}

Este estudo caracterizou a ocorrência de brisa de vale e montanha na cidade de Itajubá, MG. Para isso, foram utilizados dados de direção e intensidade do vento medidos a cada 10 minutos na estação meteorológica automática localizada no campus da Unifei. De forma geral, a direção do vento predominante em Itajubá é a norte. A presença da brisa de vale e montanha foi identificada através de gráficos de rosas do vento construídos para cada hora do dia. A brisa de montanha se estabelece entre $15-16 \mathrm{~h}$ e tem sua máxima intensidade entre 21-22 h. Já a brisa de vale se estabelece entre $07-08$ h e tem a sua máxima 

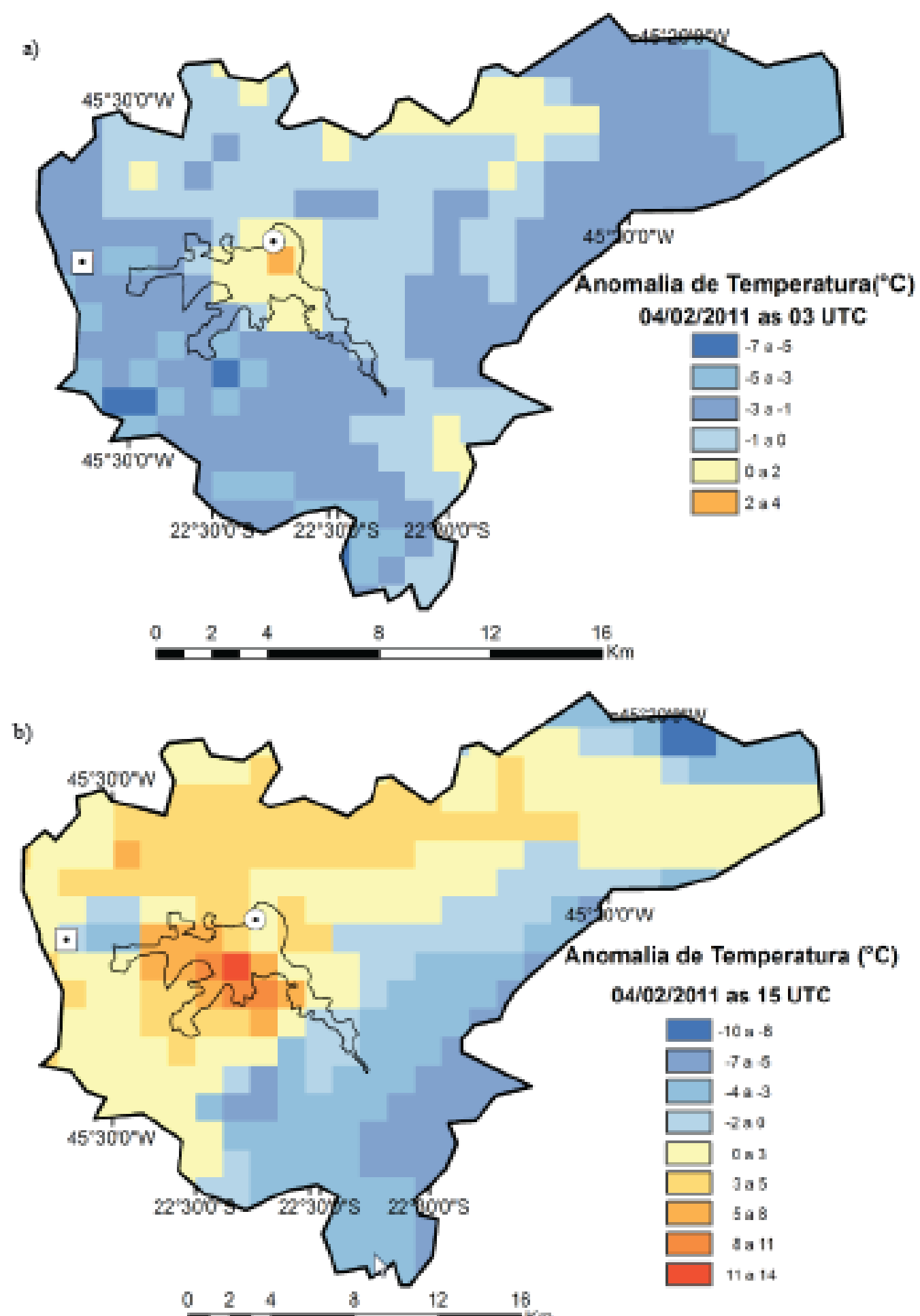

Figura 5 Anomalia de temperatura do ar à superfície (temperatura de cada pixel menos a média da temperatura dentro da mancha urbana de Itajubá que está indicada com o contorno preto no interior da figura) no dia 04 de fevereiro de 2011 às 03 UTC (a) e 15 UTC (b). O círculo indica a localização da estação meteorológica da Unifei dentro da cidade de Itajubá e o quadrado com um ponto no centro (lado esquerdo) indica uma região sem urbanização com topografia similar a da cidade de Itajubá. 


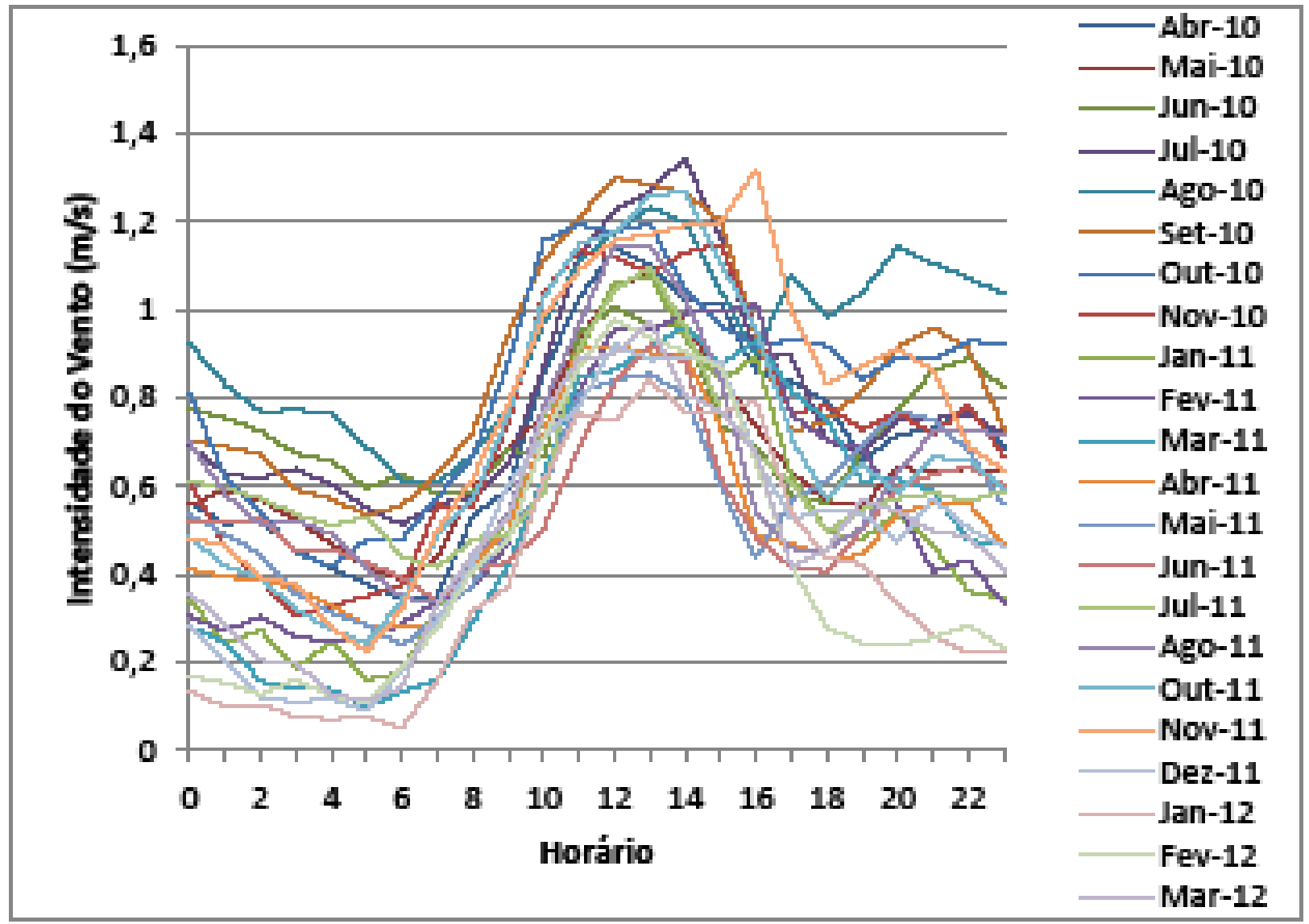

Figura 6 Média horária (m/s) da velocidade do vento em cada mês do período entre 2010 e 2012.

intensidade entre 11-14 h. Esses resultados mostram que a brisa de montanha é mais duradoura. Fato que provavelmente está associado à influencia do efeito térmico da cidade nos gradientes horizontais de temperatura entre a região montanhosa e o centro urbano, onde a cidade apresentou valores sempre maiores de temperatura quando comparado ao entorno.

\section{Referências}

ANDERSON, L. O.; LATORRE, M. L.;

SHIMABUKURO, Y. E.; ARAI, E.; JÚNIOR, O. A. de C. Sensor MODIS: uma abordagem geral. INPE-10131-RPQ/752 São José dos Campos - São Paulo, 2003.

BRAGA, M F S; KRUSCHE, N. Padrão de Ventos em Rio Grande, RS, no período de 1992 a 1995. Revista Atlântica, Rio Grande, v. 22, p. 27-40, 2000.

EOSDIS. Earth Observing System Data and Information System. Earth Observing System Clearing HOuse (ECHO) / Reverb, Version 10 [online application]. Greenbelt, MD: EOSDIS, Goddard Space Flight Center (GSFC) National Aeronautics and Space Administration (NASA). 2009. Disponível em: $<\mathrm{http}: / /$ reverb.earthdata.nasa. gov>. Acesso em: 11 mar. 2013.

HINDMAN, E. E. Air Currents in a Mountain Valley Deduced from the Breakup of a Stratus Deck. Monthly Weather Review, v. 101, n. 3, p. 195-200, 1973.

KOUSKY, V. E.; ELIAS, M. Meteorologia Sinótica. Parte I. São José dos Campos, INPE, 1982, 107 p. (INPE-2605-MD/021).

MCGREGOR, G. R., NIEUWOLT, S. Tropical Climatology: an introduction to the climates of the low latitudes. Chichester. Willey. 1977.

MORAES, O. L. L., DEGRAZIA, G. A.; FITZJARRALD, D.R., 1992: Estudo Numérico da Canalização do Vento em um Vale. In VII Congresso Brasileiro de Meteorologia. p. 576-581. 1992. 
PETITCOLIN, F., VERMOTE, E. Land surface reflectance, emissivity and temperature from MODIS middle and thermal infrared data. Remote Sensing of Environment, v. 83, p. 112 - 134, 2002.

Prefeitura Municipal de Itajubá. Dados geográficos. Disponível em:<http://www.itajuba. mg.gov.br/fis_geo.php> acesso em 18/10/2012.

SAKURAGI, J.; SOUZA, L. H. Modelagem de brisas e circulação vale-montanha para o Vale do Paraíba e Litoral utilizando o RAMS. In: XI Congresso Brasileiro de Meteorologia, 2000, Rio de Janeiro/RJ. XI Congresso Brasileiro de Meteorologia. Rio de Janeiro: Microservice Microfilmagens Reproduções Técnicas Ltda., 2000.

STEWART, J. Q. et al. A Climatological Study of Thermally Driven Wind Systems of the U.S. Intermountain West. Bulletin of the American Meteorological Society, v. 83, n. 5, p. 699-708, 2002.

STULL, R. B. Meteorology for Scientists and Engineers. 2a. Ed., United States, Brooks/Cole, 2000.

VEMADO, F. Análise da circulação de brisa marítima e seus impactos sobre a precipitação na Região Metropolitana de São Paulo por meio do modelo ARPS. Dissertação de Mestrado em Meteorologia, Universidade de São Paulo, 2012.

WAN, Z.; LI, Z. L. A physics-based algorithm for retrieving land-surface emissivity and temperature from EOS/MODIS data. IEEE Transaction on Geoscience and Remote Senece, v. 35, n.3, p. 980 - 995, July 1997.

WHITEMAN, C. D., Mountain Meteorology: Fundamentals and Applications. Oxford University Press, 2000. 355 p. 